\title{
A meta-analytic comparison of 8 methods of closed anterior shoulder dislocation reduction
}

\author{
Iqbalbhai Sadikot M. ${ }^{1}$, Samir Shah J. ${ }^{*}$ \\ DOI: https://doi.org/10.17511/ijmrr.2020.i02.12
}

1 Mariyam Iqbalbhai Sadikot, MBBS, AMC MET Medical College, Ahmedabad, Gujarat, India.

2* Jay Samir Shah, MBBS, AMC MET Medical College, Ahmedabad, Gujarat, India.

Background: Anterior shoulder dislocation is a common injury, accounting for $95 \%$ of all shoulder injuries. However, many doctors and hospitals do not have a fixed protocol for the treatment of dislocations. The current study have compared 8 different techniques for shoulder dislocation reduction in this study. Methods: Eight different methods namely the Scapular Manipulation, Matsen's Traction-Countertraction, Kocher's, Spaso, External Rotation, Cunningham, Modified Milch, and the FARES methods were compared on the basis of efficacy, pain experienced during reduction (VAS score), and time taken for reduction. Results: The Matsen's Traction-Countertraction method had the highest efficacy, while the Scapular Manipulation method had the least VAS scoring. The FARES Method had the fastest reduction time on average. Interpretation and Conclusions: As per the data analyzed, the FARES and Scapular Manipulation method appear to be the most effective in reducing anterior dislocations, having consistently high success rates, and low VAS scores and reduction times. These 2 methods may be recommended to new practitioners to treat acute shoulder dislocations.

Keywords: Shoulder Dislocation, Emergency Medicine, Orthopedics

Corresponding Author

Jay Samir Shah, MBBS, AMC MET Medical College, Ahmedabad, Gujarat, India.

Email: JaySShah7@gmail.con
How to Cite this Article

To Browse

Sadikot MI, Shah JS. A meta-analytic comparison of 8 methods of closed anterior shoulder dislocation reduction. Int J Med Res Rev. 2020;8(2):213-220. Available From

https://ijmrr.medresearch.in/index.php/ijmrr/article/ view/1139

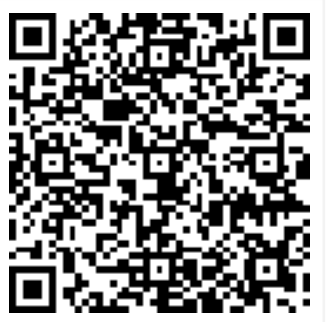

\begin{tabular}{|c|c|c|c|c|}
\hline & $\begin{array}{c}\text { Manuscript Received } \\
2020-04-06\end{array}$ & $\begin{array}{c}\text { Review Round } 1 \\
2020-04-18\end{array}$ & $\begin{array}{c}\text { Review Round } 2 \\
2020-04-23\end{array}$ & Review Round 3 \\
\hline & $\begin{array}{c}\text { Conflict of Interest } \\
\text { No }\end{array}$ & $\underset{\mathrm{Nil}}{\text { Funding }}$ & $\begin{array}{c}\text { Ethical Approval } \\
\text { Yes }\end{array}$ & $\begin{array}{c}\text { Plagiarism } \mathbf{X} \text {-checker } \\
7 \%\end{array}$ \\
\hline OPEN & $\begin{array}{l}\text { (c) } 2020 \text { by } \\
\text { ACCESS }\end{array}$ & $\begin{array}{l}\text { ai Sadikot, Jay } \mathrm{S} \\
\text { Access article lic } \\
\text { https://creative }\end{array}$ & $\begin{array}{l}\text { Published by Siddha } \\
\text { Creative Commons } \\
\text { censes/by/4.0/ unp }\end{array}$ & $\begin{array}{l}\text { earch and Social Welfare } \\
\text { International License } \\
\text { t.0]. }\end{array}$ \\
\hline
\end{tabular}




\section{Introduction}

Acute anterior shoulder dislocation is a common injury, accounting for $95 \%$ of all shoulder dislocations. [1] Several maneuvers for the reduction of the humeral head have been described with varying rates of success. The ideal method would be quick, painless, effective, and have a minimal risk for complications.

The aim of this study is to compare the efficacy of eight different methods of closed anterior shoulder dislocation, namely the Scapular Manipulation Technique, Matsen's Traction-Countertraction Method, the External Rotation, Spaso's Technique, Kocher's Method, the Cunningham Method, FARES Method, and the Modified Milch Method. The techniques of the various methods are mentioned as follows:

Scapular Manipulation: The scapular manipulation technique focuses on repositioning the glenoid fossa rather than the humeral head, and requires less force than other methods.

The arm is held at 90 degrees of forwarding flexion while traction is applied to it. Slight external rotation of the humerus may cause reduction by creating a favorable position of the humeral head to the glenoid fossa. After the traction application, the scapula is manipulated to complete the reduction. This is done by stabilizing the superior aspect of the scapula with one hand and pushing the inferior tip of the scapula medially toward the spine.

The thumb of the hand stabilizing the superior aspect of the scapula can be placed along the lateral border of the scapula and used to assist the pressure applied by the thumb of the other hand. A small degree of dorsal displacement of the scapular tip is recommended as it is being pushed as far as possible in the medial direction [2]. Attaching 3-7 $\mathrm{kg}$ (5-15 lb.) weights to the affected arm is recommended by some authors to make the traction easier as it allows the scapula to pivot around an axis and aid reduction [3].

Matsen's Traction-counter traction: The patient is placed on his/her back with a sheet around the chest and also around the assistant's waist for counter traction. The physician stands on the side of the dislocated shoulder near the patient's waist with the elbow of the dislocated shoulder bent to $90^{\circ}$. A second sheet, tied loosely around the physician's waist and looped over the patient's forearm, provides traction while the physician leans back
Against the sheet while grasping the forearm. Traction is applied to the arm with the shoulder in abduction, and the assistant applies firm countertraction to the body using a folded sheet [4].

Kocher's Method: The patient is placed supine on the examining table with the surgeon standing at his/her side. For a dislocated right shoulder, the surgeon takes the elbow in his right hand and the wrist in his left. Gentle firm traction is applied to the humerus by the right hand, and while traction is maintained, the humerus is gently and smoothly rotated laterally by moving the forearm out until the normal limit of about $60^{\circ}$ of rotation is reached. While the limb is held in lateral rotation, the elbow is brought forwards to the front of the chest. Finally, it is rotated medially and the hand is brought over the opposite shoulder [5].

Fares Method: FARES stands for fast, reliable, and safe. The patient is made to lie in a supine position. Step 1: The patient's hands are grasped, with the affected arm at the side, elbow extended and forearm in mid-prone position. Longitudinal traction is applied to the affected extremity. Simultaneously vertical oscillatory movements at the rate of 2-3 cycles/sec, in a short-range of about $5 \mathrm{~cm}$ above and below the horizontal plane, are applied throughout the whole reduction process to facilitate muscle relaxation.

The affected shoulder is then abducted slowly, with the continuation of longitudinal traction and vertical oscillatory movements. When the arm is abducted past 90 degrees it is gently externally rotated with the continuation of longitudinal traction, abduction, and vertical oscillatory movements. Usually, at 120 degrees of abduction, shoulder reduction is achieved. Once the reduction was achieved, the arm is internally rotated and the elbow is flexed to place the forearm over the chest wall [6].

Spaso Technique: The patient is placed in the supine position and the affected arm is grasped around the wrist or the distal forearm and gently lifted vertically, applying gentle traction. While maintaining vertical traction, the shoulder is slightly rotated externally. A clunk is heard and/or felt when the reduction is completed. The reduction will usually occur after a few minutes of gentle traction. The head of the humerus may be palpated and pushed to facilitate reduction while maintaining traction with the other hand [4].

External Rotation: With the patient in the supine position, traction is applied as the arm is held at 90- 
Degree elbow flexion. The arm is then adducted to the side of the chest with the shoulder placed in 20 degrees forward flexion. Using the wrist as a guide, the shoulder is externally rotated to bring the forearm into the coronal plane. Once reduction is achieved, the arm is internally rotated to bring the forearm into the abduction position and is immobilized [7].

Cunningham Method: The patient is sat up with the back vertical. The arm is adducted pointing vertically down, and the elbow flexed at 90 degrees so that the forearm points horizontally and anteriorly. The surgeon squats/kneels at the side of the patient, facing the opposite direction of the patient. The surgeon's hand is placed between the patient's forearm and body so the patient's wrist is on the surgeon's upper arm. Steady gentle traction is applied directly downwards. On the other hand, the trapezius, deltoid, and biceps brachii muscles are sequentially massaged to relax them. At this point the humeral head will usually relocate without any 'clunk', hence the shoulder must be checked regularly to confirm whether relocation has occurred [8].

Modified Milch Method: The patient is placed supine with the affected limb in adduction, elbow in 90-degree flexion, and hand resting on the abdomen. The shoulder is stabilized with one hand by placing the fingers over the top of the shoulder and thumb in the axilla, steadying the humeral head in the axilla. The elbow of the affected limb is grasped with the other hand keeping it in 90 degrees flexion. The arm is gradually abducted and externally rotated over a period of a few minutes. Abduction is done up to 120 degrees and external rotation is done till the forearm touches the bed. Upwards pressure on the humeral head with or without longitudinal traction may be applied for reduction. As the humeral head is pushed back into the glenoid, gradual adduction with the limb straightened should be attempted [9].

\section{Methodology}

Search: A comprehensive review of the literature was performed in the PubMed database, as well as searches via Google Scholar to compile a list of relevant studies. The main search terms included Shoulder Reduction, Modified Milch, Kocher, Spaso Technique, Cunningham Method, External Rotation, FARES, Kocher's, Matsen's Traction-Countertraction, Scapular Manipulation, Anterior Shoulder Dislocation Reduction, and others.
Table-1: Study characteristics.

\begin{tabular}{|l|l|}
\hline \multicolumn{1}{|c|}{ Location } & \multicolumn{1}{|c|}{ No. of Studies } \\
\hline EU & 8 \\
\hline North America & 9 \\
\hline South America & 1 \\
\hline Asia & 10 \\
\hline Oceania & 1 \\
\hline Study Language & No. of Studies \\
\hline English & 28 \\
\hline Icelandic & 1 \\
\hline No. Of Dislocations & 1838 \\
\hline No. of Successful Reductions & 1660 \\
\hline Success Percentage & $90.31 \%$ \\
\hline Method of Reduction & No. of Attempted Reductions \\
\hline FARES & 247 \\
\hline Cunningham Method & 195 \\
\hline Scapular Manipulation & 232 \\
\hline Matsen's Traction-Countertraction & 196 \\
\hline External Rotation & 432 \\
\hline Spaso Technique & 134 \\
\hline Kocher's Method & 236 \\
\hline Modified Milch Method & 166 \\
\hline Studies with VAS & 10 \\
\hline Studies Reporting Reduction Time & 13 \\
\hline
\end{tabular}

Study Selection: Randomized Control Trials and Prospective Studies of patients with either first time or recurrent anterior shoulder dislocations were included. There were no limitations on the participant's age, gender, or nationality. The focused intervention was the use of any of the eight methods to reduce the dislocation during the first attempt at reduction. The control included standard care which may or may not has been any of the listed methods. Studies with more than one interventional group were included only if the patients were randomized. Trials were excluded if they included reduction methods not performed by medically licensed individuals. Cases which required open reduction were excluded.

Data Abstraction: Two reviewers extracted data independently according to predefined criteria including the first author, size of the study, the intervention of experimental and control group, and the main conclusion. Any discrepancies were discussed until the authors reached consensus.

Data Synthesis and Analysis: Successful reduction on the first attempt using any reduction method was used to calculate any method's success rate. The mean reduction times of the various methods were also compared. The mean Visual 
Analog Scale (VAS) (0-10) scale scores were compared as a method for identifying pain experienced by the patients to attempt to standardize patient pain scoring.

Statistical Analysis: The primary objective of the analysis was to examine the clinical efficacy of various methods of shoulder reduction. A standard value of $P=0.05$ was used to establish statistical significance for all comparisons. A chi-square test was used to establish a difference in the efficacy of the reduction of all the different methods. One-way ANOVA tests were used to establish a significant difference in the VAS scores and the mean reduction time. Based on the clinical data available, reduction time could be compared between all methods except the Modified Milch, and VAS scoring could be compared between all methods except the Modified Milch and External Rotation method. All studies were performed with the use of Microsoft Excel. All summary results were expressed with means with SDs.

\section{Results}

Study Characteristics: A total of 29 studies were selected consisting of 1,838 dislocations.[2-4,4,611,11-16,16-30]. Study characteristics are summarized in Table 1 . Studies were conducted in North America (9), South America (1), Europe (8), Asia (10), and Oceania (1). The average success percentage for a reduction on the first attempt was 90.3\%. 28 studies were reported in English, and 1 study was reported in Icelandic. 10 studies provided information on the Visual Analog Scale of pain while 13 studies reported the reduction time for each method of reduction. All studies did not report the gender ratio for patients, however for the studies that did report the gender of patients, there were significantly more males than females $(p<0.05)$.

Table-2: Efficacy of various methods.

\begin{tabular}{|l|l|}
\hline \multicolumn{1}{|c|}{ Method of Reduction } & \multicolumn{1}{|c|}{ Efficacy } \\
\hline Matsen's Traction-Countertraction & $97.96 \%$ \\
\hline Cunningham Method & $95.38 \%$ \\
\hline FARES & $93.52 \%$ \\
\hline Modified Milch Method & $92.17 \%$ \\
\hline Scapular Manipulation & $91.38 \%$ \\
\hline External Rotation & $87.04 \%$ \\
\hline Spaso Technique & $85.07 \%$ \\
\hline Kocher's Method & $83.05 \%$ \\
\hline
\end{tabular}

Treatment Characteristics: A total of eight methods were analyzed. In all studies, reductions were performed by licensed doctors, including
Residents and attending surgeons. All reductions were performed in a hospital setting.

Meta-analytics Results: The outcomes with sufficient data were available for a statistical analysis to be performed. The outcomes for pain scaling and reduction time were expressed as means and their 95\% confidence intervals.

Efficacy of Various Methods: The treatment efficacy of various methods is seen in Table 2. There was a significant difference in the efficacy of the eight techniques. The Matsen's TractionCountertraction Method had the highest efficacy, with a success rate of $97.9 \%$, while The Kocher's Technique was least effective with the efficacy of $83.05 \%$.

Table-3: Pain experienced during reduction.

\begin{tabular}{|l|l|l|c|}
\hline \multicolumn{1}{|c|}{ Technique } & Mean VAS Score & SD & $95 \%$ CI \\
\hline Scapular Manipulation & 1.6 & 0.9 & 1.04 to 2.16 \\
\hline FARES & 1.78 & 0.97 & 1.51 to 2.05 \\
\hline Matsen's Traction-Countertraction & 4.34 & 2.12 & 3.58 to 5.10 \\
\hline Kocher's & 5.27 & 1.62 & 4.04 to 6.50 \\
\hline Spaso's Technique & 6.5 & 2.8 & 4.46 to 8.54 \\
\hline
\end{tabular}

Pain Experienced: The VAS Scale (1-10) was reported by 10 studies to quantify the pain experienced by the patient during reduction. The results are summarized in Table 3. The External Rotation method, Cunningham Method and Modified Milch Method could not be assessed due to a lack of reported VAS scores. Of the five techniques with sufficient data, the Scapular Manipulation Technique was the least painful technique with a mean VAS score of 1.6 (SD = 0.9). The 95\% confidence interval was $1.03-2.16$. The Spaso's Technique was the most painful as reported by patients, with a mean VAS score of $6.5(\mathrm{SD}=2.8,95 \% \mathrm{CI}=4.46-$ 8.54).

Table-4: Reduction time.

\begin{tabular}{|l|l|l|l|}
\hline \multicolumn{1}{|c|}{ Technique } & Time & \multicolumn{1}{c|}{ SD } & \multicolumn{1}{c|}{$95 \%$ CI } \\
\hline FARES & 1.41 & 0.517 & 1.33 to 1.48 \\
\hline Scapular Manipulation & 2.4 & 1.8 & 1.77 to 3.3 \\
\hline External Rotation & 3.73 & 2.2 & 3.32 to 4.13 \\
\hline Kocher's & 3.96 & 2.13 & 3.46 to 4.46 \\
\hline Spaso's Technique & 4.8 & 1.5 & 4.33 to 5.27 \\
\hline Matsen's Traction-Countertraction & 6.57 & 4.26 & 5.82 to 7.32 \\
\hline
\end{tabular}

Mean Reduction Time: Mean reduction time was analyzed for all methods except the Cunningham Method and Modified Milch method due to the lack of data. The mean reduction time was measured from the time of initiation of treatment to the 
Moment the dislocation was reduced. Of the 6 methods, the FARES method was the fastest, taking a mean of 1.41 minutes ( $S D=0.517,95 \% \mathrm{CI}=$ 1.33 to 1.49). The Matsen's Traction-Countertraction Method took the most time, with a mean of 6.57 minutes per reduction $(S D=4.26,95 \% C I=5.82-$ 7.31).

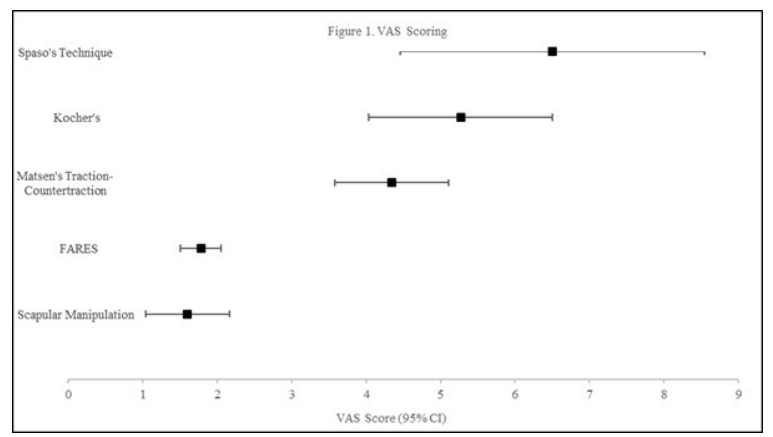

Fig-1: VAS scoring.

\section{Discussion}

For the vast majority of documented medical history, more than 2 millennia, the method introduced by Hippocrates was the standard method for shoulder dislocation [31]. Since that time, multiple methods have been reported in the literature and used. However, the protocol for the management of an acute anterior shoulder dislocation is not standardly available in all hospitals.[19] No one method has a $100 \%$ rate of success, but a comparison of different methods can guide practitioners to select an efficient method, which ultimately helps treat the patient better. This could also lead to the formulation of a standard protocol to follow to reduce dislocations.

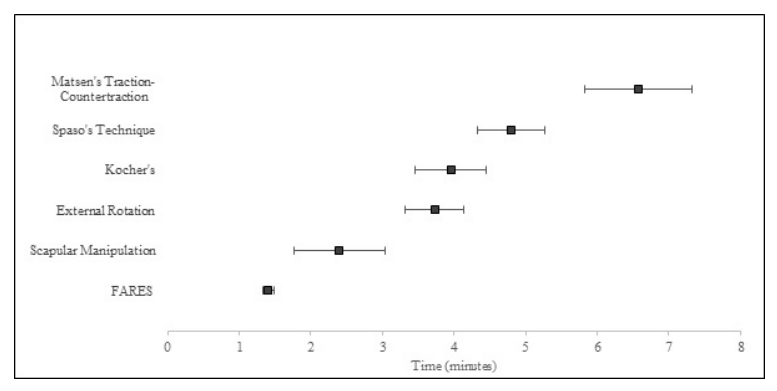

Fig-2: Mean reduction time.

The results suggest that Matsen's TractionCountertraction method has the most efficacy. However, it has the largest mean reduction time and has an above-average (more pain) rating on the VAS scale of the techniques compared in this study. This method also requires an assistant to apply
Appropriate countertraction and requires the patient to be fully relaxed, which may not be possible in all clinical situations [4]. The large reduction time maybe because of the use of two separate flexible sheets.

The FARES technique stands for "Fast, Safe and Reliable", which concurs with the data analyzed by this study, showing the FARES technique has the least reduction time. It was designed to not require sedatives or analgesia, which also is consistent with the data, having the second least VAS score. It has an above-average success rate, making it a lucrative choice for many surgeons attempting to reduce an anterior shoulder dislocation. However, awareness of this technique is not widespread, having been introduced only in 2009 [32].

The Scapular Manipulation technique may also be considered for more frequent use, having the least pain, one of the shortest mean reduction times, and an above-average success rate. It is also said to be one of the easiest to perform methods, being suitable for new physicians. Introduced in 1979, the scapular manipulation technique is already one of the most commonly performed techniques for reduction [3].

The Spaso Technique, first introduced in 1998, has one of the longest times of reductions and highest pain scores of the techniques mentioned here [33]. However, many physicians find the Spaso technique easier to perform, and the force needed for reduction is also less compared to other techniques. Counter-traction on the axilla is not needed on the axilla in the Spaso technique, reducing the risk of damaging the brachial plexus $[23,34]$. These features may have led to it being adopted by many surgeons.

Kocher's technique has been previously labeled as 'unphysiological, dangerous, and brutal' due to its association with fractures of the surgical neck of the humerus. However, it has been reported this only occurs when surgeons forcibly try to overcome the muscle spasm, which should be treated with analgesia or sedation, or another method should be applied to reduce the dislocation [35]. This study found the Kocher's method to have a high VAS score, and the lowest success rate of all the maneuvers mentioned here, which may be due to the above-mentioned reasons.

The Cunningham method is shown to have one of the highest success rates. It was designed to be 'drug-free' and hence not require analgesia or 
Sedation, which may have played a role in the above results [8]. The Modified Milch technique is a modification of the Milch Technique, designed to both make reduction easier for the surgeon and less painful for the patient, decreasing but not necessarily eliminating the need for analgesic or sedative medication [9]. The External Rotation Method had a fairly average reduction time and efficacy. However, the use of sedation is fairly common with this method. [7]However, not all factors are quantifiable when choosing a method to use, and many doctors may have different preferences and needs.

\section{Limitations}

There are several limitations to the analysis. Due to the lack of published data, a linkage to age could not be established. Also, the distorting effects of publications on meta-analysis' are well documented [36]. The present study may also be affected in the heterogeneity of different surgeons, including the time one technique is attempted before being declared a failure, the familiarity with different techniques, etc. VAS scoring and mean reduction times were not published for the majority of the studies. The length of hospital stays as well as long term complications could be analyzed in future studies.

\section{Conclusion}

The technique of choice to treat shoulder dislocations ultimately is chosen by the doctor/clinic itself. However, further analysis of various methods could help to improve the efficacy of treatment. Currently, the FARES Method and Scapular Manipulation method appear to be the most effective for reducing acute anterior shoulder dislocations.

\section{What does the study add to the existing knowledge}

The study lays out the advantages and disadvantages of several methods of shoulder reduction in order to create a basis for practicing and future physicians to treat anterior shoulder dislocation patients effectively.

\section{Author's contributions}

Dr. Mariyam Sadikot: Project Design, Manuscript Preparation, Literature Search, Data Acquisition,
Data Analysis, Manuscript Editing, and Manuscript Review.

Dr. Jay Shah: Manuscript Preparation, Literature Search, Data Acquisition, Data Analysis, and Manuscript Editing.

\section{Reference}

01. Cutts S, Prempeh M, Drew S. Anterior Shoulder Dislocation. Ann R Coll Surg Engl. 2009;91(1)27. doi: [Article] [Crossref]

02. McNamara RM. Reduction of anterior shoulder dislocations by scapular manipulation. Ann Emerg Med. 1993;22(7)1140-1144. doi: [Article] [Crossref]

03. Baykal B, Sener S, Turkan H. Scapular manipulation technique for reduction of traumatic anterior shoulder dislocations- experiences of an academic emergency department. Emerg Med J EMJ. 2005;22(5)336-338.

doi: [Article] [Crossref]

04. Watson-Jones R. Fractures and joint injuries, In6th ed. Churchill Livingstone. 1982.

[Crossref]

05. Vasudevan TK, Ramlal RD, Samraj A. Success outcome of reduction in anterior shoulder dislocation by FARES method. Int J Res Med Sci. 2017;3(12)3858-3862. doi: [Article] [Crossref]

06. Marinelli $M$, de Palma L. The external rotation method for reduction of acute anterior shoulder dislocations. J Orthop Traumatol Off J Ital Soc Orthop Traumatol. 2009;10(1)17-20. doi: [Article] [Crossref]

07. Cunningham N. A new drug free technique for reducing anterior shoulder dislocations. Emerg Med Fremantle WA. 2003;15(5-6)521-524. doi: [Article] [Crossref]

08. Garnavos C. Technical note modifications and improvements of the Milch technique for the reduction of anterior dislocation of the shoulder without premedication. J Trauma. $1992 ; 32(6) 801-803$. doi: [Article] [Crossref]

09. Kothari RU, Dronen SC. Prospective evaluation of the scapular manipulation technique in reducing anterior shoulder dislocations. Ann Emerg Med. 1992;21(11)1349-1352.

doi: [Article] [Crossref] 
10. Sahin N, Oztürk A, Ozkan Y, Atıcı T, Ozkaya G. A comparison of the scapular manipulation and Kocher's technique for acute anterior dislocation of the shoulder. Eklem Hast Ve Cerrahisi Jt Dis Relat Surg. 2011;22(1)28-32.

[Crossref]

11. Anderson D, Zvirbulis R, Ciullo J. Scapular manipulation for reduction of anterior shoulder dislocations. Clin Orthop. 1982;(164)181-183. [Crossref]

12. Ghane $M-R$, Hoseini $S-H$, Javadzadeh $H-R$, Mahmoudi S, Saburi A. Comparison between traction-countertraction and modified scapular manipulation for reduction of shoulder dislocation. Chin J Traumatol. 2014;17(2)93-98. doi: [Article] [Crossref]

13. Boger D, Sipsey J, Anderson G. New traction devices to aid reduction of shoulder dislocations. Ann Emerg Med. 1984;13(6)423-425.

doi: [Article] [Crossref]

14. Singh S, Yong CK, Mariapan S. Closed reduction techniques in acute anterior shoulder dislocation modified Milch technique compared with traction-countertraction technique. J Shoulder Elbow Surg. 2012;21(12)1706-11.

doi: [Article] [Crossref]

15. Maity A, Roy DS, Mondal BC. A prospective randomised clinical trial comparing FARES method with the Eachempati external rotation method for reduction of acute anterior dislocation of shoulder. Injury. 2012;43(7)10661070.

doi: [Article] [Crossref]

16. Jeyarajan R, Cope AR. Anaesthesia for reduction of anterior dislocations of the shoulder. Arch Emerg Med. 1992;9(1)71.

doi: [Article] [Crossref]

17. Danzl DF, Vicario SJ, Gleis GL, Yates JR, Parks DL. Closed reduction of anterior subcoracoid shoulder dislocation, Evaluation of an external rotation method. Orthop Rev. 1986;15(5)311315.

[Crossref]

18. te Slaa RL, Wijffels MPJM, Marti RK. Questionnaire reveals variations in the management of acute first time shoulder dislocations in the Netherlands. Eur J Emerg Med Off J Eur Soc Emerg Med. 2003;10(1)5861.

doi: [Article] [Crossref]
19. Banerjee A. Is anaesthesia necessary for reducing shoulder dislocation?. Arch Emerg Med. $1990 ; 7(3) 240$. doi: [Article] [Crossref]

20. Mirick MJ, Clinton JE, Ruiz E. External rotation method of shoulder dislocation reduction. J Am Coll Emerg Physicians. 1979;8(12)528-531. doi: [Article] [Crossref]

21. Fernández-Valencia JA, Cuñe J, Casulleres JM, Carreño A, Prat S. The Spaso technique- a prospective study of 34 dislocations. Am J Emerg Med. 2009;27(4)466-469. doi: [Article] [Crossref]

22. Yuen $M-C$, Yap $P-G$, Chan $Y-T$, Tung $W-K$. An easy method to reduce anterior shoulder dislocation the Spaso technique. Emerg Med J. 2001;18(5)370-372. doi: [Article] [Crossref]

23. Rezende B da RM, de Almeida JI, de Sousa UJ, Bomfim L de S, Ferreira MS. Glenoumeral dislocation- a prospective randomized study comparing spazo and kocher maneuvers. Acta Ortop Bras. 2015;23(4)192-196.

doi: [Article] [Crossref]

24. Beattie TF, Steedman DJ, McGowan A, Robertson CE. A comparison of the Milch and Kocher techniques for acute anterior dislocation of the shoulder. Injury. 1986;17(5)349-352.

doi: [Article] [Crossref]

25. Berkenblit SI, Hand MB, MacAusland WR. Reduction of skiing-related anterior shoulder dislocation using Kocher's method without traction. Am J Orthop Belle Mead NJ. 2000;29(10)811-814.

[Crossref]

26. Royle G. Treatment of acute anterior dislocation of the shoulder. $\mathrm{Br} J$ Clin Pract. 1973;27(11)403-404.

[Crossref]

27. PR C, PR C, PR N, P SM, Azeem A. Modified Milch Technique - A Safe and Painless Method for Reduction of Anterior Shoulder Dislocation. Int J Med Res Rev. 2014;2(5)439-443. doi: [Article] [Crossref]

28. Gudmundsson TH, Bjornsson HM. [Reduction of shoulder dislocation with the Cunningham method]. Laeknabladid. 2017;103(9)373-376. doi: [Article] [Crossref] 
29. Tsoi L, Wong M. FARES Method to Reduce Acute Anterior Shoulder Dislocation- A Case Series and an Efficacy Analysis. Hong Kong J Emerg Med. 2012;19(1)65-69.

doi: [Article] [Crossref]

30. Regauer M. Neurovascular complications due to the Hippocrates method for reducing anterior shoulder dislocations. World J Orthop. 2014;5(1)57.

doi: [Article] [Crossref]

31. Sayegh FE, Kenanidis EI, Papavasiliou KA, Potoupnis ME, Kirkos JM, Kapetanos GA. Reduction of acute anterior dislocations: a prospective randomized study comparing a new technique with the Hippocratic and Kocher methods. J Bone Joint Surg Am. 2009;91(12)2775-2782.

doi: [Article] [Crossref]
32. Miljesic S, Kelly A-M. Reduction of anterior dislocation of the shoulder the Spaso technique. Emerg Med. 1998;10(2)173-175.

doi: [Article] [Crossref]

33. Yuen $M-C$, Tung $W-K$. The use of the Spaso technique in a patient with bilateral dislocations of shoulder. Am J Emerg Med. 2001;19(1)64-66. doi: [Article] [Crossref]

34. Gleeson AP. Anterior glenohumeral dislocationswhat to do and how to do it. Emerg Med J. 1998;15(1)7-12. doi: [Article] [Crossref]

35. Egger M, Smith GD. Bias in Location and Selection of Studies. BMJ. 1998;316(7124)6166.

doi: [Article] [Crossref] 